\title{
Social robotics to help children with autism in their interactions through imitation
}

\author{
Valentina Pennazio
}

University of Macerata, Italy, valentina.pennazio@unimc.it, orcid.org/0000-0002-3915-1880

\begin{abstract}
This article aims to reflect on the main variables that make social robotics efficient in an educational and rehabilitative intervention. Social robotics is based on imitation, and the study is designed for children affected by profound autism, aiming for the development of their social interactions. Existing research, at the national and international levels, shows how children with autism can interact more easily with a robotic companion rather than a human peer, considering its less complex and more predictable actions. This contribution also highlights how using robotic platforms helps in teaching children with autism basic social abilities, imitation, communication and interaction; this encourages them to transfer the learned abilities to human interactions with both adults and peers, through human-robot imitative modelling. The results of a pilot study conducted in a kindergarten school in the Liguria region are presented. The study included applying a robotic system, at first in a dyadic child-robot relation, then in a triadic one that also included another child, with the aim of eliciting social and imitative abilities in a child with profound autism.
\end{abstract}

Keywords: social robotics, imitation, interaction, autism, kindergarten

\section{Introduction}

Currently, there are different types of robots: some are prebuilt, autonomous and highly sophisticated (e.g. Interactive RObotic Social MEdiators as Companions [IROMEC], NAO and MILO); others are more flexible (e.g. the Lego ${ }^{\circledR}$ MindStorms ${ }^{\text {TM }}$ construction kit) (Erwin, 2001) because they are built to include the children while designing and building different robots with specific behavioural characteristics (Akermann, 2002). Robotics experiments conducted in recent years in kindergarten and primary schools included especially the usage of robotic kits such as Bee-bot and Lego WeDo (Battegazzorre, 2009), which are parts of educational robotics (Leroux, 1999). These experiments are associated with a variety of educational situations focussing on how to use robots as a learning instrument (Caci 2004) while evoking multidisciplinary aspects (Garbati, 2012; Strollo, 2008). This is a new research area that has developed from the constructivist paradigm (Piaget and Inhelder, 1966), later revised by Papert's $(1980,1993)$ constructionist approach, which considers robotic technologies as "objects to think with" (Harel and Papert, 1991). The strong relation with the narration is the strength of this type of robotic educational systems. In such a structured technological environment, it is possible to witness sociability promotion, cooperative work and co-construction of knowledge (Ackermann, 2002).

However, this type of robotics is not useful in environments with children with disabilities (e.g. forms of profound autism). In these cases, it is better to refer to the area of social robotics, which, through the application of sophisticated platforms, has the aim of teaching children basic social abilities, imitation, communication and interaction (Tapus et al., 2007). In fact, various research reports show that children with autism prefer robots to human beings (Robins et al., 2005). Humanoid robots, which highly resemble humans but are less complex, help a child with autism to transfer the abilities that have been learned with the robot and interiorised through imitative modelling to human interactions thereafter. Physical imitation (Di Nuovo et al., 2014) naturally develops: sometimes it is structured, as the children are actively encouraged by adults or by the robot itself to imitate the actions (Duquette et al. 2008); in other cases, it spontaneously develops as part of a game in which the child and the robot reciprocally imitate their behaviours (Robins et al., 2009). This game can also be extended to triadic interactions among a child with autism, an adult and a robot. 
This article presents a reflection on the main characteristics that make social robots useful in an interaction with a child with profound autism, and results are reported on the application of the robotic platform IROMEC in a case study that took place in kindergarten schools.

\section{State of the art}

The positive role of robotic technologies in sustaining the cognitive, affective and social development of children with different types of special educational needs through play has been confirmed by numerous studies in this sector (Marti \& Giusti, 2009; Cook, Adams, Volden, Harbottle \& Harbottle, 2011; Pearson \& Borenstein, 2013; Robins \& Dautenhahnn, 2014). Those studies used prototypes specifically built to be utilised by children with physical and cognitive disabilities or those affected by autism (Kaspar, Paro, IROMEC and NAO) (Dautenhahn et al., 2009; Shibata et. al., 2001; Marti, 2005; Kulk and Welsh, 2008). However, there also are reports of use of robotic toys that can be easily found in commerce (I-Sobot, Wall-E, Mst. Personality) and that are suitable for children with special needs (Benitez \& Cala, 2007). The chosen variables focussed on the impact of the ludic utilisation of robotic platforms on cognitive, imitative and communicative-linguistic development of children and the consequences on their social conduct. The educational and therapeutic effectiveness of using these robots was evaluated in experimental contexts, mostly in rehabilitative interventions based on play.

Research (Cook and Polgar, 2008) shows how robotic systems have been used in replacement of standardised tests, whenever the latter cannot be administered because of motor or linguistic impairments, to inferentially evaluate the abilities of the child with disability regarding the understanding of abstract thinking and problem-solving abilities. Those used were robots especially designed to solicit the activation of specific cognitive abilities in the child and, at the same time, develop open environments that can enable discoveries, explorations and problem solving. Recent experiments conducted on autism cases have studied acceptability (De Graaf et al., 2013), use of NAO (Gouaillier et al., 2009), a robotic platform of socially assistive robotics (SAR) (e.g. Kim et al., 2013), as well as interaction and attention maintenance using the robotic platform MILO. Currently, an experiment has been started at Gaslini Hospital (Genoa, Italy), guided by the Italian Institute of Technologies (Istituto Italiano di Tecnologia), which includes the robotic platform iCub, with the aim of helping children with autism to learn "motor communication" through imitation (Cavallo et al., 2016; Ansuini et al., 2015).

\subsection{Types of social robots}

When talking about social robotics, it is necessary to distinguish between different types of robots.

Assistive robotics (AR): The term includes robots that assist the individual with disabilities through a physical interaction. The link with assistive technologies (e.g. robotic prosthetic limbs that enable children with physical disability to play with Lego bricks) is evident (Cook et al, 2011).

Socially interactive robotics (SIR): The term includes robots that have elicitation of social interactions as the main aim (Fong et al., 2003).

SAR: The term includes robots that create a close and effective interaction with the individual, without focussing on physical contact, giving assistance to improve rehabilitation and learning (Feil-Seifer and Matarić, 2005, 2009; Rabbitt, Kazdin and Scassellati, 2014). SAR systems are different from typical social robotic applications (e.g. SIR) as they have to help the user, motivate him/her and influence a change in his/her behaviour (Scassellati, Admoni and Matarić, 2012). They use neutral interaction strategies, including language, facial expressions and communicative gestures, with the aim of giving assistance that varies according to the specific intervention context (Feil-Seifer and Matarić, 2005).

Cognitive robot companions: The term includes robots of more recent creation. They have the role of being at the service of human beings, as expert assistants or companions, as "adaptive servants" that constantly coexist and interact with the user. Those robots have to learn new abilities, take care of new tasks and grow in constant interaction and cooperation with human beings. In addition, they have specific human-robot interaction characteristics that are not simply functional but also emotional and social (Marti, Giusti, 2009), making interactions more entertaining, intriguing, significant and similar to human ones.

It is necessary to choose the best robotic system depending on the disability. Regarding children with autism, SAR robots are useful as they encourage social relations and learning through imitation (Goodrich et al., 2011; Villano et al., 2011). The "robotic companions" can be used with several types of disabilities, as they are accessible, modular, social and active.

\section{Why use social robots}

Due to its high level of interactivity and the presence of sophisticated personalising functions (Rabbitt, Kazdin, Scassellati 2014), robotics can be positively used to decrease difficulties that follow the distress typical of social 
isolation (Lehmann et al. 2011); this promotes an increase of motivation and the acquisition of cognitive and relational complex competences.

The reasons that justify using robotics in activities with children with autism are numerous. Firstly, robots represent "real objects" that exist and concretely act in the external world. They can move in a three-dimensional space and physically interact with people and the environment. Secondly, adjustable sensory stimulation can promote a more significant perceptive experience, compared to that offered by a simple videogame. Thirdly, a robotic system is more easily perceived as an "independent and intelligent agent", even if with visible limitations. It can be seen as a sort of "play mate" that can mediate activities in cooperative situations. The way in which the robot can simulate human behaviour is fundamental in the social and affective development of children affected by autism, guiding them in the complex world of social interactions. It is also necessary to highlight that if a robotic system is used to help the child to develop his/her social abilities, this instrument does not replace adults or peers within an activity. Conversely, the robot as a "social mediator" should nurture, support and constantly solicit interaction and imitation, while creating a link between children with serious communicative/relational difficulties and their peers.

\subsection{Modularity and configurability}

In order to understand rehabilitative/educational interventions that can be designed using robotic systems, it is necessary to clarify the characteristics that lead to the unanimous identification of a robot for autism, specifically, the ability to navigate in the environment, to move some body parts and to induce an emotional involvement due to its humanoid aspect and the interaction that it activates. The capability of enacting autonomous behaviours in relation to stimuli coming from the environment or from the person (e.g. avoiding obstacles, reacting to touch and so on) and the possibility to be programmed to carry out different types of complex behaviours (combinations or sequences of movements, sounds, lights and so on) are also essential.

Modularity and configurability are two of the main characteristics that a robotic device must have in order to be easily utilised in an educative context. These concepts gain importance in relation to the fact that children with autism, whom the intervention is built for, even if with the same diagnosis, are very different, needing specific and individualised interventions.

Modularity means that different functions should be activated in distinct modules; different possible combinations of design are achievable, so that it is possible to create a change in the robot functionality. For example, a robot can be built in three separate modules: module A associated with movement functions, module B related to functions of the head and facial expressions and module $\mathrm{C}$ associated with auditory retroactions (sounds and vocal messages) and vocal recognition. By assembling those three modules in different ways, it is possible to create four different types of robots: a mobile robot with facial expressions and head movements $(\mathrm{A}+\mathrm{B})$; a mobile robot with facial expressions, head movements and vocal interactions $(\mathrm{A}+\mathrm{B}+\mathrm{C})$; a mobile robot controllable through voice $(\mathrm{A}+\mathrm{C})$; and a still robot with a head, showing facial expressions and activated by vocal commands that can reproduce output vocal messages $(\mathrm{B}+\mathrm{C})$. Other advantages that can be obtained from modularity include the fact that it is always possible to add new modules related to specific requirements that need to be met.

Configurability concerns the possibility of modifying some variables in relation to specific functions. For example, different variables can be modified in relation to the needs of the child regarding the action "moving on the ground": certain speed, acceleration and specific directions. Even the functions related to auditory feedback should be manipulated by increasing or decreasing sound, as visual feedback should provide the addition of lights and colours, hiding or making visible animated images.

Thus, modularity makes it possible to create robots with different functions; configurability enables to create a robot with functions that are specific for the activities and are built based on the needs of the child.

\subsection{Social function}

Another element that should distinguish robots designed for children with autism is sociability, meant as the ability of the robots to sustain the social model to which they refer and the complexity of interactive scenarios (Breazeal, 2003; Marti, 2005). The risk linked to an excessive physical and behavioural resemblance with human beings or animals is that of building a high expectation in the interlocutor, often let down during the interaction with the robot, which is unable to fulfil very complex requests (Marti, 2005). This is why it is necessary to provide for a usage of robots in which it is clear from the first interaction that they have an imperfect system (Norman, 1994; Marti, 2005), openly manifesting their limits. Imitation of human characteristics is related not just to physical or cognitive aspects but also to emotion expressions, recognition and control. Artificial emotions are used as part of the design of social robots to increase the level of credibility in the interaction; to give feedback to the user about internal states of the robot and its intention; and to help understand how some environmental factors can influence the behaviour of the robot. Robots can manifest emotional states in different ways: turn light-emitting diode (LED) lights on or off to show excitement, as well as control eyebrows, ears, eyes, lashes, lips and neck movements, to the extent of producing a high variety of emotive expressions (Breazeal, 2003). It is necessary, however, to distinguish when the emotion expression in the robots is the aim of the interaction and when it is intended as an element of mediation of human activity (Marti, 2005). 


\subsection{Social robots agentivity}

It is possible to share someone else's emotions through a psychological process that allows one to recognise emotions in other individuals through a discriminative mechanism that first focusses on facial expressions, then on body movements, gestures, language and acting in general. Recognition becomes a basic requirement to understand the perspective of others and distinguish it from that of the individual himself/herself; this makes it possible to share other people's emotions and being able to represent them (Marti, 2005). The discrimination is only possible if the other person is recognised as an agentive, an animated subject that has intentions and aims and is able to manifest his/her internal states. Attributing "agentivity" to social robots is primary and depends on some physical perceptive characteristics. Morphology, for instance, is closely linked with the idea of agentive (Johnson, Morton, 1991; Marti, 2005), as tactile experience is. This makes it possible to distinguish between an animate and inanimate object (Smith and Heise, 1992; Marti, 2005), as well as behavioural characteristics such as eye movements, gaze direction, head movements and autonomous movements, in opposition to those caused by external causes (Rakison and Poulin-Dubois, 2001; Scholl and Tremoulet, 2000; Marti, 2005). What characterises an agentive more is its ability to establish reciprocal and contingent relationships with other agentives, being able to manage them even without immediate physical proximity (Marti, 2005), e.g. following someone else's gaze or feeling fearful after someone else manifests fear (Baron-Cohen, 1995).

\subsection{Sociability and imitation through robotics}

Robotics is a useful intervention tool in educational and rehabilitative environments as, from the different configurations that can be implemented (modularity and configurability), the robot can be adapted to the different needs of the child (Dautenhahn et al., 2001; D'Ambrosio et al., 2003; Cardaci et al., 2004; Dautenhahn et al., 2007). The behaviour of the robot can be gradually modified, introducing subtle changes every time that a new activity is performed. In addition, its physical aspects, which are simpler compared to the appearance of a human being, provide the child reassurance, faith and the idea of being in control of the situation.

The possibility of working in a context where peers are present and structured rules need to be followed can help children with autism to both experiment with social abilities and gain positive results. However, unpredictable behaviours enacted by peers make it very hard to achieve them. On this level, robotics can help to maintain the structure of the rules within a specific context or activity stable, making the robot a useful mediator between the child with autism and his/her peers.

\section{A pilot study}

The synthetic description of a pilot study that was conducted for about 6 months with a child with profound autism in a kindergarten school in Liguria is reported here. The intention of the study was to analyse the correct usage of a social robot; define the actions and activities that can be done to guide the child in learning emotional states; and verify the possible transaction from a robot to a human (teacher or child) communication.

\subsection{The robotic instrument}

The robot IROMEC was used in this study. This robot was developed in the Sixth Research and Development Programme (VI Programma Quadro di Ricerca e Sviluppo), as a prototype of a "companion robot" that can act as mediator in rehabilitative and educational contexts, using the concept of modularity. Action scenarios that are implemented in IROMEC are five in total, but only two were used in this study: Turn Taking and Generating Contact.

\subsection{Experimental setting}

The IROMEC robot is controlled by APM devices with a specific software. It was placed at the centre of the gym, conveniently delimitated, in a bright and quiet environment, so that the robot was guaranteed a wide movement area. In order to register all the events and be able to measure the variables during the interactions, a video camera was placed such that it did not interfere with the experimentation. The researcher conducted the experiment operating the robot remotely, while the teacher had the function of guaranteeing a familiar environment and helping the child in its activities when necessary, while standing behind him/her.

\subsection{Procedure}

The experiment was designed with a progressive increase of the interaction and the activity was programmed so that it could be flexibly interrupted if the child did not want to participate anymore (Conti et al., 2015). The following steps were designed. 
Preliminary observation in a natural context through a specifically designed template was the first step.

It made it possible to collect information on the level of inclusion of the child in everyday activities, how much the individual was included by other children, predisposition to interaction and autonomy in affective and relational aspects (reassurance, willingness to following rules). The information collected was used to structure activities and the level of difficulty.

Phase 1 - Free exploration

The child was prodded by the teacher to explore the switched-on robot set in a static mode. The child specifically had to touch the various parts of the robot, explore the part representing the face and that showing its state (quiet, resting, happy and so on) (focalisation of attention on the static object). Subsequently, the child was asked by the teacher to follow the moving robot and be chased by it (focalising on the moving object).

Phase 2 - Generating contact

The child was guided by the teacher in an activity involving the interpretation of the emotions of the robot, which were the consequences of actions towards the robot (cause-effect relations). He/she was asked to imitate the behaviours enacted by the robot. It consisted of a physical imitation game, in which the role of the child was to put in effort as an imitator or as a starter. During this phase, the device to control the robot was hidden from the child. Positive reinforcement was released by the robot when the child was able to imitate the movements or guidance was given when repeated mistakes were made or the child got distracted from the aim.

Phase 3 - Dyadic interaction

In this phase, the role of the teacher was taken by a peer and the request was to start an interaction through a turntaking activity, started between the peer and the teacher with the aim of encouraging the child to spontaneously take part in an activity and apply the social behaviours stimulated by previous activities in a human interaction.

Phase 4 - Final phase

In this phase, the robot was programmed to communicate to the human that it needed to recharge its batteries; in this way, it is possible to focus on the limitations of the robot and satisfy the ethical requirement of separation.

\subsection{Data collection}

Behaviours were recorded and evaluated through videotaping of the experimental sessions, using a questionnaire divided as follows and separately completed by two researchers, which were then compared. Several behaviours were recorded simultaneously (e.g. sight and touch).

In order to analyse the interaction, the four criteria of Robins et al. (2005) were used to evaluate basic behaviour: eye contact, touch, imitation/closeness and human interaction.

\section{Results and discussion}

Eye contact measurements showed an increase associated with higher attention levels. Specifically, an increase in eye contact with the static robot was measured, and it remained constant during movement and change of position of the robot. In the last phase, an interesting increase of eye movement from the teacher to the robot to the peer and then back to the robot was highlighted. Eye contact maintenance was activated by the latent intention of reaching for the object and manipulating it.

Significant touch-related elements are associated with eye contact and attention. In the preliminary phase, an increase of tactile exploration of the robot was evident, especially in the face area. In the final phase, the desire of getting close to the robot with the whole body, in a sort of hug, was recorded.

The child showed a high ability in enacting facial expressions showed by the robot (happiness, fear, sadness, worry and pleasure) and behaviours (flight, proximity and so on) throughout the range of activities.

Human interaction showed positive results in the last phase, in which the child moved from a passive audience-like role (looking at the interaction between teacher and peer) to an active role. There are two significant elements: the first one is linked to imitation, as the child enacted the same actions that he/she saw in the robot, the teacher and the peer while he/she was observing; the second one is related to the interaction, meaning a change from looking for contact (strokes, hugs) from the robot to contact from the teacher and then the peer.

\section{Conclusions}

The results of this pilot study will have to be confirmed by analysing a wider sample; however, currently, they confirm previous results already reported in literature (Robins et al., 2005), encouraging the realisation of specific intervention protocols that include the robot as a mediator between the child with autism and the human interlocutor (child or adult). 
The increase of attention and eye contact/movement, as well as of imitative and interactive abilities, needs to be considered as the first step towards a positive change in the sociability of the child. It is anyway evident that the most significant results could be obtained with continuous interventions that should be developed over a longer time frame.

\section{References}

Ackermann, E. (2002). Ambienti di gioco programmabili: cos'è possibile per un bambino di quattro anni. TDTecnologie Didattiche, 27, 48-55.

Ansuini, C., Cavallo, A., Bertone, C. \& Becchio, C. (2015). Intentions in the Brain: The Unveiling of Mister Hyde. The Neuroscientist 21(2), 126-135. DOI: 10.1177/1073858414533827

Battegazzorre, P. (2009). Bee-bot, fare robotica con un giocattolo programmabile a banalità limitata. Atti Didamatica: Retrieved from http:/www.itctannoia.it/Didamatica/2009/lavori/battegazzore.pdf.

Baron-Cohen, S. (1995). Mindblindness, An essay on blindness and theory of mind. Cambridge: MIT Press.

Benitez, A., Cala A. (2007). Market research. Report del progetto IROMEC. www.iromec.org

Breazeal, C. (2003). Toward sociable robots. Robotics and Autonomous Systems, 42, 167-175.

Caci, B. (2004). Laboratorio di robotica: una palestra per la mente. Proceeding del Congresso Nazionale dell'Associazione Italiana di Psicologia (AIP), Sezione di Psicologia Sperimentale, Sciacca.

Cardaci, M., Caci, B.\& D’Amico, A. (2004). La robotica nella riabilitazione di soggetti autistici e con deficit cognitivi. Proceedings of the conference "Tecnologie Digitali e l'Intelligenza Artificiale al Servizio dei Disabili". Italy: University of Palermo.

Cavallo, A., Koul, A., Ansuini, C., Capozzi, F. \& Becchio, C. (2016). Decoding intentions from movement kinematics. Scientific Reports, 6:37036. DOI: 10.1038/srep37036

Conti, D., Di Nuovo, S., Buono, S., Trubia, G. \& Di Nuovo, A. (2015). Use of robotics to stimulate imitation in children with Autism Spectrum Disorder: A pilot study in a clinical setting. Proceedings of the 24th IEEE International Symposium on Robot and Human Interactive Communication. Kobe. Japan.

Cook, A.M. \& Polgar, J.M. (2008). Cook \& Hussey's Assistive Technologies: Principles and Practice. Philadelphia: Elsevier Inc.

Cook, A.M, Adams, K., Volden, J., Harbottle, N. \& Harbottle, C. (2011). Using Lego robots to estimate cognitive ability in children who have severe physical disabilities. Disability and Rehabilitation: Assistive Technology, 6 (4), 338-346.

D’Ambrosio, M. Mirabile, Miglino, O. (2003). Uno studio pilota sull'impiego di giocattoli robotici nella riabilitazione cognitiva. Proceedings of the National Congress of the Italian Psychology Association (AIP). Bari, Italy.

Dautenhahn, K., Werry, I., Ogden, B. \& Harwin, W. (2001). Can Social Interaction Skills Be Taught by a Social Agent? The Role of a Robotic Mediator. Autism Therapy, Proceedings CT, The Fourth International Conference on Cognitive Technology: Instruments of Mind (CT2001). University of Warwick, United Kingdom, Springer Verlag.

Dautenhahn, K. \& Robins, B. (2007). Learning and Interaction in Children with Autism. VI IEEE International Conference on Development and Learning, London, United Kingdom, July 11-13.

Dautenhahn, K., Nehaniv, C., Walters, M., Robins, B., Kose-Bagci, H., Mirza, A. \& Blow, M. (2009). KASPAR - A Minimally Expressive Humanoid Robot for Human-Robot Interaction Research, to appear. Special Issue on "Humanoid Robots" for Applied Bionics and Biomechanics 6, 3-4, 369-397.

De Graaf, M.M.A. \& Ben Allouch, S. (2013). Exploring influencing variables for the acceptance of social robots. Rob. Auton. Syst., 61, 1476-1486

Di Nuovo, S., De La Cruz, V., Conti, D., Buono, S., Di Nuovo, A. (2014). Mental Imagery: rehabilitation through simulation. Life Span and Disability 17, 1, 89-118

Duquette, A., Michaud, F. \& Mercier, H. (2008). Exploring the use of a mobile robot as an imitation agent with children with low-functioning autism. Auton. Robots, 24, 147-157

Erwin, B. (2001). Creative Projects with LEGO Mindstorms. Boston: Addison-Wesley Pub Co.

Feil-Seifer, D. \& Matarić, M.J. (2005). Defining Socially Assistive Robotics. Rehabilitation Robotics, ICORR 2005, 465-468.

Feil-Seifer, D. \& Matarić M.J. (2009). Toward Socially Assistive Robotics for Augmenting Interventions for Children with Autism Spectrum Disorders. Springer Tracts in Advanced Robotics, 54, 201-210.

Fong, T., Nourbakhsh, I. \& Dautenhahn K. (2003). A Survey of Socially Iteractive Robots. Robotics and Autonomous Systems, 42 (3-4), pp. 143-166.

Garbati, M. (2012). Robotica: sempre più presente nella nostra vita. Retrieved from

http://www.torinoscienza.it/dossier/robotica_sempre_piu_presente_nella_nostra_vita_22645.html 30/05/2014.

Goodrich, M., Colton, M., Brinton, B. \& Fujiki, M. (2011). A case for lowdose robotics in autism therapy. Proceedings of the 6th ACM/IEEE International Conference on Human/Robot Interaction, 143-144.

Gouaillier, D., Hugel, V., Blazevic, P., Kilner, C., Monceaux, J., Lafourcade, P., Marnier, B., Serre, J.\& Maisonnier, B. (2009). Mechatronic design of NAO humanoid. IEEE International Conference on Robotics and Automation, 21242129

Harel I. \&Papert, S. (1991). Constructionism. New Jersey: Ablex Publishing Corporation. 


\section{Social robotics to help children with autism in their interactions through imitation \\ Pennazio}

IROMEC Consortium, Deliverable 1.0. User needs report, www.iromec.org

Johnson, M.H. \& Morton, J. (1991). Biology and Cognitive Development: The case of face recognition. Blackwell: Oxford.

Kim, K.J., Park, E. \& Shyam Sundar, S. (2013). Caregiving role in human-robot interaction: A study of the mediating effects of perceived benefit and social presence. Computer Human Behavior 29, 1799-1806.

Kulk, J. \& Welsh, J. (2008). A Low Power Walk for the NAO Robot. Retrieved from http://www.araa.asn.au/acra/acra2008/papers/pap117s1.pdf?origin=publication detail 10.03. 20172014

Lehmann, H., Marti, P. \& Robins, B. (2011). Robots as social mediators for children with Autism - A preliminary analysis comparing two different robotic platforms. Proceedings of the First International Conference on Development and Learning (ICDL) and the International Conference on Epigenetic Robotics (EpiRob), Frankfurt, Germany, 24-27 August.

Leroux, P. (1999). Educational Robotics. International Journal of Artificial Intelligence in Education, 10, pp. 10801089.

Marti,P. (2005). L'interazione Uomo-Robot. Ergonomia 2, 50-57.

Marti, P. \& Giusti, L. (2009). A robot Companion for Inclusive Games: a user-centred design perspective. Proceedings of IEEE International Conference on Robotics and Automation, Anchorage, 3-8 maggio.

Norman, D.A. (1994). How Might People Interact with Agents. Communications of the ACM 37 (7), July 1994, 68-71.

Papert, S. (1980). Mindstorms: children, computer, and powerful ideas. New York: Basic Books.

Papert, S. (1993). The Children's Machine. Rethinking school in the age of computer. New York: Basic Books.

Pearson, Y. \& Borenstein, J. (2013). The Intervention of Robot Caregivers and the Cultivation of Children's Capability to Play. Science and Engineering Ethics. 19 (1), 123-137.

Piaget, J.\&Inhelder, B. (1966). La Psychologie de l'enfant. Paris: PUF.

Rabbitt, S.M, Kazdin, A.L \& Scassellati, B. (2014). Integrating Socially Assistive Robotics into Mental Healthcare Interventions: Applications and Recommendations for Expanded Use. Clin Psychol Rev. 2015 Feb;35:35-46. doi: 10.1016/j.cpr.2014.07.001

Rakison, D.H. \& Poulin-Dubois, D. (2001). The developmental origin of the animate-inanimate distinction. Psychological Bulletin,2, 209-228.

Robins, B. \& Dautenhahn, K. (2014), Tactile Interactions with a Humanoid Robot: Novel Play Scenario Implementations with Children with Autism. International Journal of Social Robotics. Retrieved from http://download.springer.com/static/pdf/578/art\%253A10.1007\%252Fs12369-014-02280.pdf?auth66=1404289696_ff11915700c75528370176e76e39777f\&ext $=$.pdf 12.03 .2017

Robins, B., Dautenhahn, K. \& Dickerson, P. (2009). From isolation to communication: a case study evaluation of robot assisted play for children with autism with a minimally expressive humanoid robot, Procs of 2 nd Int Conf on Advances in Computer-Human Interaction: ACHI'09. vol. 2009, IEEE, 205-211. DOI: 10.1109/ACHI.2009.32

Robins, B., Dautenhahn, K., Te Boekhorst, R. \& Billard, A. (2005). Robotic assistants in therapy and education of children with autism: can a small humanoid robot help encourage social interaction skills?, Univers. Access Inf. Soc., 4, 2, 105-120

Scassellati, B., Admoni, H. \& Matarić, M. (2012). Robot for use in autism research. Annual Review of Biomedical Engineering, 14, 275-294.

Scholl, B.J. \&Tremoulet, P.D. (2000). Perceptual causality and animacy. Cognitive Science, 4, pp 22-28.

Shibata, T., Wada, K., Saito, T. \& Tanie K. (2001). Mental Commit Robot and its Application to Therapy of Children. Proceedings of the IEEE/ASME International Conference On AIM 01, Como, Italy.

Smith,L.B. \& Heise, D. (1992). Perceptual similarity and conceptual structure. In Burn, B. Percepts, concepts and categories. Ed. Elseiver.

Strollo, M.R. (2008). Scienze cognitive e aperture pedagogiche. Nuovi orizzonti nella formazione degli insegnanti, Franco Angeli, Milano.

Tapus, A., Matarić, M.J.\& Scassellati, B. (2007). Socially assistive robotics. Grand Challenges of Robotics, IEEE Robot. Autom. Mag., 14

Villano M., Crowell C.R., Wier K., Tang K., Thomas B., Shea N., ... Diehl J.J. (2011), DOMER: A Wizard of Oz interface for using interactive robots to scaffold social skills for children with Autism Spectrum Disorders. HumanRobot Interaction, 279-280. 